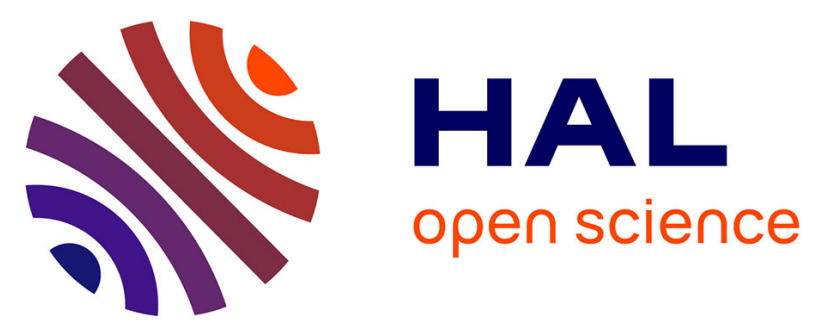

\title{
Exploring contacts of eRF1 with the 3'-terminus of the $P$ site tRNA and mRNA stop signal in the human ribosome at various translation termination steps
}

Konstantin Bulygin, Dmitri Graifer, Codjo Hountondji, Ludmila Frolova, Galina Karpova

\section{To cite this version:}

Konstantin Bulygin, Dmitri Graifer, Codjo Hountondji, Ludmila Frolova, Galina Karpova. Exploring contacts of eRF1 with the 3'-terminus of the P site tRNA and mRNA stop signal in the human ribosome at various translation termination steps. Biochimica et Biophysica Acta - Gene Regulatory Mechanisms , 2017, 1860 (7), pp.782-793. 10.1016/j.bbagrm.2017.04.004 . hal-01906422

\section{HAL Id: hal-01906422 \\ https://hal.sorbonne-universite.fr/hal-01906422}

Submitted on 8 Nov 2018

HAL is a multi-disciplinary open access archive for the deposit and dissemination of scientific research documents, whether they are published or not. The documents may come from teaching and research institutions in France or abroad, or from public or private research centers.
L'archive ouverte pluridisciplinaire HAL, est destinée au dépôt et à la diffusion de documents scientifiques de niveau recherche, publiés ou non, émanant des établissements d'enseignement et de recherche français ou étrangers, des laboratoires publics ou privés. 


\title{
Exploring contacts of eRF1 with the 3 '-terminus of the P site tRNA and mRNA stop signal in the human ribosome at various translation termination steps
}

\author{
Konstantin N. Bulygin $^{\mathrm{a}}$, Dmitri M. Graifer ${ }^{\mathrm{a}, \mathrm{b}}$, Codjo Hountondji ${ }^{\mathrm{d}}$, Ludmila Yu. Frolova ${ }^{\mathrm{c}, *}$, \\ Galina G. Karpova, ${ }^{\mathrm{a}, \mathrm{b}, *}$ \\ a Institute of Chemical Biology and Fundamental Medicine, SB RAS, Novosibirsk 630090, Russia \\ b Novosibirsk State University, Novosibirsk 630090, Russia \\ c Engelhardt Institute of Molecular Biology, RAS, Moscow 119991, Russia \\ ' Sorbonne Universités UPMC Univ Paris 06, Unité de Recherche UPMC UR6 "Enzymologie de l'ARN", F-75252 Paris Cedex 05, France
}

Keywords:

Human ribosome

Translation termination

Release factors eRF1 and eRF3

CCA end of tRNA

mRNA stop signal

Ribosomal decoding site

Site-directed cross-linking

\begin{abstract}
A B S T R A C T
Here we employed site-directed cross-linking with the application of tRNA and mRNA analogues bearing an oxidized ribose at the 3 -terminus to investigate mutual arrangement of the main components of translation termination complexes formed on the human 80S ribosome bound with $\mathrm{P}$ site deacylated tRNA using eRF1•eRF3•GTP or eRF1 alone. In addition, we applied a model complex obtained in the same way with eRF1•eRF3•GMPPNP. We found that eRF3 content in the complexes with GTP and GMPPNP is similar, proving that eRF3 does not leave the ribosome after GTP hydrolysis. Our cross-linking data allowed determining locations of the 3'-terminus of the P site tRNA relatively the eRF1 M domain and of the mRNA stop signal toward the $\mathrm{N}$ domain and the ribosomal decoding site at the nucleotide-peptide resolution level. Our results indicate that locations of these components do not change after peptide release up to post-termination pre-recycling state, and the positioning of the mRNA stop signal remains similar to that when eRF1 recognizes it. Besides, we found that in all the complexes studied eRF1 shielded the N-terminal part of ribosomal protein eS30 from the interaction with the nucleotide adjacent to stop codon observed with pre-termination ribosome free of eRFs. Altogether, our findings brought important information on contacts of the key structural elements of eRF1, tRNA and mRNA in the ribosomal complexes including those mimicking different translation termination steps, thereby providing a deeper understanding of molecular mechanisms underlying events occurring in the course of protein synthesis termination in mammals.
\end{abstract}

\section{Introduction}

Synthesis of the normal size proteins in all organisms from bacteria to higher eukaryotes is ensured by translation termination that occurs when one of the three stop codons of the mRNA, UAA, UGA or UAG, reaches the ribosomal acceptor (A) site. In eukaryotes, all three stop signals are decoded by the same termination factor eRF1, which is responsible for peptidyl-tRNA hydrolysis preceding the nascent peptide release and is delivered to the ribosomal A site within the ternary complex with GTP and GTPase eRF3. After stop codon recognition by eRF1, eRF3 splits GTP to GDP followed by rapid hydrolysis of peptidyltRNA. A wealth of biochemical and mutational data has suggested that the highly conserved motifs in the N-terminal domain of eRF1, namely,
GTS, TASNIKS and YxCxxxF, are important for stop codon recognition, while the universal tripeptide GGQ in the middle (M) domain is required for the hydrolysis of peptidyl-tRNA in the ribosomal peptidyl transferase center (PTC) [1-4]. Application of mRNA analogues bearing photoactivatable cross-linkers in the stop signal targeted to the ribosomal A site has revealed that in the termination complexes uridine in the first position contacts TASNIKS motif [5], whereas purines in the second and third positions interact with GTS and YxCxxxF motifs [6,7]. Cross-linking data [7], which are in agreement with NMR data [8], have also indicated that the $\mathrm{N}$ domain of eRF1 can adopt different conformations to recognize stop signal adenines and guanines.

Recently, structures of model eukaryotic termination complexes have been deciphered by high resolution cryo-electron microscopy

\footnotetext{
* Corresponding authors at: Novosibirsk Institute of Chemical Biology and Fundamental Medicine, SB RAS, Novosibirsk 630090, Russia; Engelhardt Institute of Molecular Biology, RAS, Moscow 119991, Russia

E-mail addresses: frolova@eimb.ru (L.Y. Frolova), karpova@niboch.nsc.ru (G.G. Karpova).
} 
(cryo-EM) [9-14]. Cryo-EM data have confirmed direct implication of the three conserved motifs of the eRF1 $\mathrm{N}$ domain in stop codon recognition and have provided a number of important details concerning positioning of eRFs relative to the ribosomal components and the $P$ site tRNA molecule. The comparison of structures of pre-termination complexes containing eRF1•eRF3•GMPPNP $[9,10,13]$ or only eRF1 lacking hydrolytic activity towards peptidyl-tRNA [14] with those of post-termination complexes containing eRF1 alone [13] or along with the ribosome recycling factor ABCE1 [11] revealed considerable difference in positioning of the GGQ tripeptide relative to the PTC in these complexes. In pre-termination complexes, this tripeptide was located far away from the PTC $[9,10,13]$, indicating inactive eRF1 state. Conversely, in the complexes imitating post-termination stages, the $\mathrm{M}$ domain was considerably shifted so that the keystone eRF1 tripeptide appeared directly in the PTC in close proximity to the 3 '-terminus of the $\mathrm{P}$ site tRNA $[11,13]$. The similar shift of the eRF1 M domain has been revealed in the complex mimicking the termination stage following GTP hydrolysis immediately prior to the peptidyl-tRNA hydrolysis [12].

However, despite significant breakthrough in studying the eukaryotic ribosomal termination complexes by means of cryo-EM, definite issues concerning both the sequence of events occurring during the translation termination and interactions between participants of these events remain unclear. In particular, interrelations between the activation of the eRF3 GTPase and interactions of eRF1 with both mRNA stop signal and deacylated tRNA occurring at the P site after the peptidyltRNA hydrolysis are not well understood. In addition, it is not exactly known at which step of termination eRF3 dissociates from the ribosomal complex. A widely accepted idea is that after GTP hydrolysis eRF3-GDP leaves the ribosome, and only then eRF1 promotes hydrolysis of peptidyl-tRNA (e.g., see [12,14]), although another possibility has been considered that eRF3 might remain bound at the ribosomal complex after GTP hydrolysis [15]. Our earlier data on chemical footprinting of rRNA backbone in various model human $80 \mathrm{~S}$ ribosomal termination complexes have provided information on particular rRNA sites undergoing rearrangements upon eRFs binding and pointed out that eRF3 does not leave the ribosomal complex after GTP hydrolysis [16].

In this study, we used specific antibodies against eRF3 to examine its content in the $80 \mathrm{~S}$ ribosomal complex corresponding to the termination step immediately after the GTP hydrolysis and peptide release compared to that in a model complex containing eRF1, eRF3, non-hydrolysable analogue GMPPNP and deacylated P site tRNA. An approach based on cross-linking of a $3^{\prime}$-dialdehyde tRNA derivative to eRF1 was applied to monitor contacts of the factor with the 3 '-terminus of the P site tRNA in these complexes as well as in the termination complex formed with eRF1 alone. Besides, we explored interactions of backbone of nucleotide in the $4^{\text {th }}$ position of stop signal with protein components of all the above complexes with the use of a 3 -dialdehyde mRNA analogue. It is worth noting that the termination complex mimicking a step after hydrolysis of both GTP and peptidyl-tRNA but before ABCE1 binding, which was applied here, had not yet been studied by cryo-EM. We obtained direct evidence that at this step eRF3 remains bound to the ribosomal complex and the GGQ motif of eRF1 resides at the ribosomal PTC close to the 3 '-terminus of the P site tRNA, while stop codon interacts with the $\mathrm{N}$ domain of eRF1 at the ribosomal decoding site. Besides, we revealed a specific feature allowing discrimination between the termination complexes and pre-termination ribosome free of eRFs in addition to that found earlier [17]. Our results demonstrate that in general positioning of the 3 '-terminus of the $\mathrm{P}$ site tRNA relative to the $\mathrm{M}$ domain of eRF1 and of stop signal toward the $\mathrm{N}$ domain of eRF1 in the ribosomal decoding site remains similar from the step occurring immediately after the peptidyl-tRNA hydrolysis up to the post-termination pre-recycling state.

\section{Materials and methods}

\subsection{Ribosomes, $t R N A, m R N A$ analogues and release factors}

$40 \mathrm{~S}$ and $60 \mathrm{~S}$ ribosomal subunits were isolated from unfrozen human placenta according to [18], reactivated by incubation in buffer A (50 mM HEPES-KOH, pH 7.5, $100 \mathrm{mM} \mathrm{KCl,} 10 \mathrm{mM} \mathrm{MgCl}_{2}$, and $0.5 \mathrm{mM}$ EDTA) for $10 \mathrm{~min}$ at $37^{\circ} \mathrm{C}$, and reassembled, taken in a $40 \mathrm{~S}: 60 \mathrm{~S}$ ratio of $1: 1.3$. Activity of the obtained $80 \mathrm{~S}$ ribosomes in poly(U)-directed binding of $\left[{ }^{14} \mathrm{C}\right]$ Phe-tRNA ${ }^{\text {Phe }}$ was about $80 \%$ (maximum binding level $1.6 \mathrm{~mol}$ of Phe-tRNA ${ }^{\text {Phe }}$ per $1 \mathrm{~mol}$ of the ribosomes). $\left[{ }^{14} \mathrm{C}\right]$ Phe-tRNA ${ }^{\text {Phe }}$ (1300 pmol/A260 unit) from Escherichia coli was kindly provided by Dr. V.I. Katunin (National Research Center "Kurchatov Institute" B.P. Konstantinov St. Petersburg Nuclear Physics Institute). Yeast tRNA ${ }^{\text {Asp }}$ (1400 pmol/A260 unit) was purified by counter-current chromatography, followed by separation by acid urea polyacrylamide gel electrophoresis (PAGE). Oligoribonucleotides used as mRNA analogues were from Sigma-Aldrich. Oligoribonucleotide derivative bearing a photoactivatable group at the $3^{\prime}$-phosphate was obtained according to [19] and it was labeled at the $5^{\prime}$-end with $\left[\gamma^{3}{ }^{32} \mathrm{P}\right]$ ATP by means of T4 polynucleotide kinase (produced at the Laboratory of Bioorganic Chemistry of Enzymes, Institute of Chemical Biology and Fundamental Medicine (ICBFM), SB RAS) before use. Periodate-oxidized oligoribonucleotide (mRNAox) was prepared from the 5'-labeled one as described [20]. Generation of DNA constructs containing sequences encoding for human eRF1 (full length) and eRF3 (lacking the nonessential $\mathrm{N}$-terminal 138 amino acids) and preparation of the respective recombinant proteins were performed according to [21-23]; eRF1 mutants bearing amino acid replacements in 60-73 positions were obtained as described [5]. The activity of release factors was examined as described $[24,25]$.

\section{2. $\left[3^{\prime}-{ }^{32} \mathrm{P}\right]$-labeled tRNA analogue}

At first, tRNA ${ }^{\text {Asp }}$ was truncated for two nucleotides from the $3^{\prime}$-end (tRNA ${ }^{\text {Asp }}-\Delta \mathrm{CA}$ ) as previously described [26] and subsequently $3^{\prime}$ labeled with the use of T4-RNA-ligase (Promega) and $\left[{ }^{32} \mathrm{P}\right] \mathrm{pCpA}$, which was obtained by 5 '-labeling of dinucleotide CpA (kindly provided by $\mathrm{Dr}$. A.G. Ven'yaminova, ICBFM SB RAS, Novosibirsk, Russia) as described above. Periodate-oxidized analogue of $\mathrm{tRNA}^{\mathrm{Asp}}\left(\mathrm{tRNA}_{\mathrm{ox}}^{\mathrm{Asp}}\right)$ was prepared as described [20].

\subsection{Ribosomal complexes, cross-linking procedure and analysis of proteins} isolated from the cross-linked 805 ribosomal complexes

Ribosomal complexes containing mRNA analogue with stop codon targeted to the A site, $\mathrm{P}$ site tRNA/tRNA $\mathrm{ox}_{\mathrm{ox}}^{\mathrm{Asp}}$ and release factors (or without factors) were obtained and purified according to [16]. At first, the respective ternary ribosome complexes with mRNA analogue and the tRNA/tRNA ${ }_{\text {ox }}^{\text {Asp }}$ were assembled by incubation of $80 \mathrm{~S}$ ribosomes $(0.5 \mu \mathrm{M})$ with the above ligands taken at $5 \mu \mathrm{M}$ concentration in buffer $\mathrm{A}$ at $20^{\circ} \mathrm{C}$ for $40 \mathrm{~min}$ (where specified, one of the ligands was omitted in control experiments). To fill the ribosomal A site with eRF1•eRF3•GMPPNP, eRF1•eRF3•GTP or eRF1 alone, the ternary ribosome complexes were incubated in the same buffer for $40 \mathrm{~min}$ at $20^{\circ} \mathrm{C}$ with the respective release factors and GTP/GMPPNP. Both eRF1 and eRF3 were taken in the eightfold excess each over the ribosomes and the final concentrations of GTP and GMPPNP were $1 \mathrm{mM}$. After the completion of incubation, the reduction of Schiff bases generated by tRNA ${ }^{\text {Asp }}{ }_{\text {ox }}$ or mRNAox was carried out by the treatment of the respective mixtures with sodium cyanoborohydride according to [27]. The cross-linked $80 \mathrm{~S}$ ribosomal termination complexes were purified from unbound ligands by centrifugation in $15-30 \%$ sucrose $(w / w)$ linear gradient in buffer $A$ (rotor SW40, 17h, 21,800 rpm, $4^{\circ} \mathrm{C}$ ). The content of eRF3 in the purified complexes was examined by dot blot assay utilizing rabbit polyclonal anti-eRF3 antibodies (1/2000 dilution) (Novus Biologicals), 
a method employed for examination of eRF1 content in similar complexes [16]. Amounts of eRF3 in the complexes were calculated by scanning of the respective signals displayed on nitrocellulose membrane with application of the ChemiDoc XRS imaging system (Bio-Rad) using a calibration curve obtained by means of definite amounts of eRF3 blotted to the same membrane. Cross-linking of ribosomes with photoactivatable mRNA analogue bearing an aryl azide group at the 3'-terminal phosphate was performed by irradiation of the respective complex with mild UV light $(\lambda>290 \mathrm{~nm})$ according to [19]. Proteins isolated from the 80S ribosomal complexes purified after cross-linking procedure by centrifugation in sucrose density gradient were analyzed by one-dimensional (1D) PAGE in the presence of SDS (1D SDS-PAGE) as described [19].

\subsection{Analysis of the cross-linked ribosomal proteins by $2 D P A G E$}

Ribosomal proteins modified with mRNAox were analyzed by 2D PAGE in a system where separation in the first dimension was in an $8 \%$ gel containing $8 \mathrm{M}$ urea at $\mathrm{pH} 8.6$ and in the second dimension in a $12.5 \%$ gel containing SDS at pH 6.7 [28]. The protein sample for the 2D PAGE analysis was prepared as described [29]. Briefly, the protein sample preparation consisted of such steps as dissociation of crosslinked $80 \mathrm{~S}$ ribosomal complexes into $40 \mathrm{~S}$ and $60 \mathrm{~S}$ subunits, their separation by centrifugation in $10-30 \%$ sucrose density gradient, ethanol precipitation of $40 \mathrm{~S}$ subunits, extraction of $40 \mathrm{~S}$ proteins into $66 \%$ acetic acid according to [30] and their precipitation by addition of 6 volumes of acetone.

\subsection{Mapping of cross-linking sites on proteins by their CNBr-induced digestion}

Isolation of proteins (eRF1, ribosomal protein (rp) eL42 or rp eS30) cross-linked to tRNA or mRNA analogues in the termination complexes, $\mathrm{CNBr}$-induced cleavage of the cross-linked proteins and separation of the resulting fragments by SDS-PAGE in a tris-tricine system were carried out as described [6]. Prior to CNBr hydrolysis, purified 80S termination complexes obtained in the presence of $\left[3^{\prime}{ }^{32} \mathrm{P}\right]$-labeled tRNA ox $_{\text {Asp }}$ were treated with $5 \mathrm{U} / \mu \mathrm{l}$ of RNase T1 ("Thermo Scientific") in buffer $\mathrm{A}$ for $1 \mathrm{~h}$ at $37^{\circ} \mathrm{C}$.

\section{Results}

3.1. Ribosomal termination complexes, eRF3 content in the complexes and cross-linking

In this study for the assembly of model human $80 \mathrm{~S}$ ribosomal termination complexes, we utilized a set of short mRNA analogues containing triplet UUC or GAC targeted to the P site by cognate tRNA ${ }^{\text {Phe }}$ or $\mathrm{tRNA}^{\mathrm{Asp}} / \mathrm{tRNA}_{\mathrm{ox}}^{\mathrm{Asp}}$, respectively, and stop codon immediately after this triplet, which occurred at the A site upon the P site tRNA binding. These complexes differed from each other by ligands bound to $80 \mathrm{~S}$ ribosomes associated with mRNA analogue and tRNA/tRNA ${ }^{\mathrm{Asp}}$ ox and were similar to those applied earlier in various studies of eRF1 interactions during translation termination [5-7,16,31]. Complex 1 comprised $\mathrm{eRF} 1 \cdot \mathrm{eRF} 3 \cdot \mathrm{GMPPNP}$ and resembled the state of stop codon recognition with the difference that the P site tRNA was deacylated; peptidyl-tRNA could not be applied here since the approach used in this study required free 3 '-terminus of tRNA capable of oxidation to a dialdehyde, which can form zero-length cross-links with proteins. Complex 2 obtained with the use of eRF1•eRF3•GTP corresponded to a state after hydrolysis of both GTP and peptidyl-tRNA. Complex 3 contained eRF1 alone, representing an intermediate state of the translation termination process that arises before recycling of the post-termination complex. The complexes were assembled, as in the previous studies [5-7,16,31], under conditions of relatively high $\mathrm{Mg}^{2+}$ concentration $(10 \mathrm{mM})$, ensuring stable binding of the ligands to the
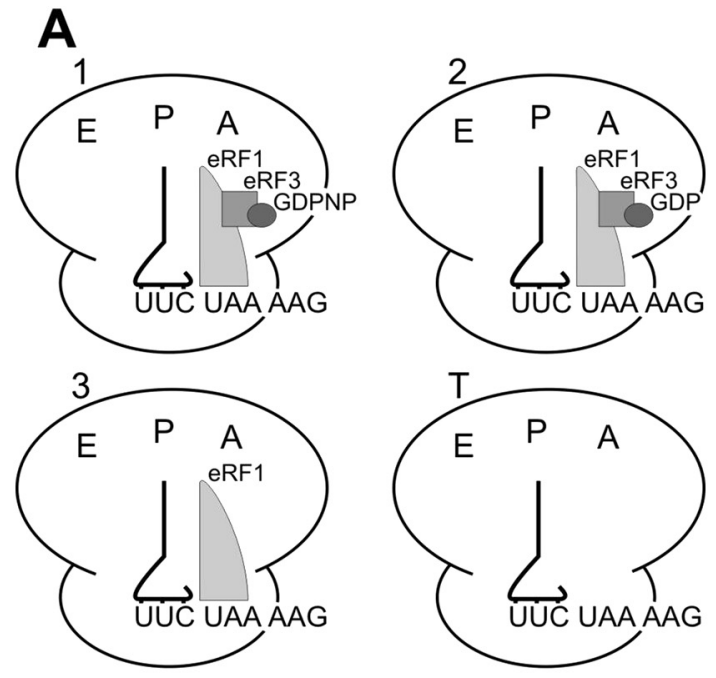

B

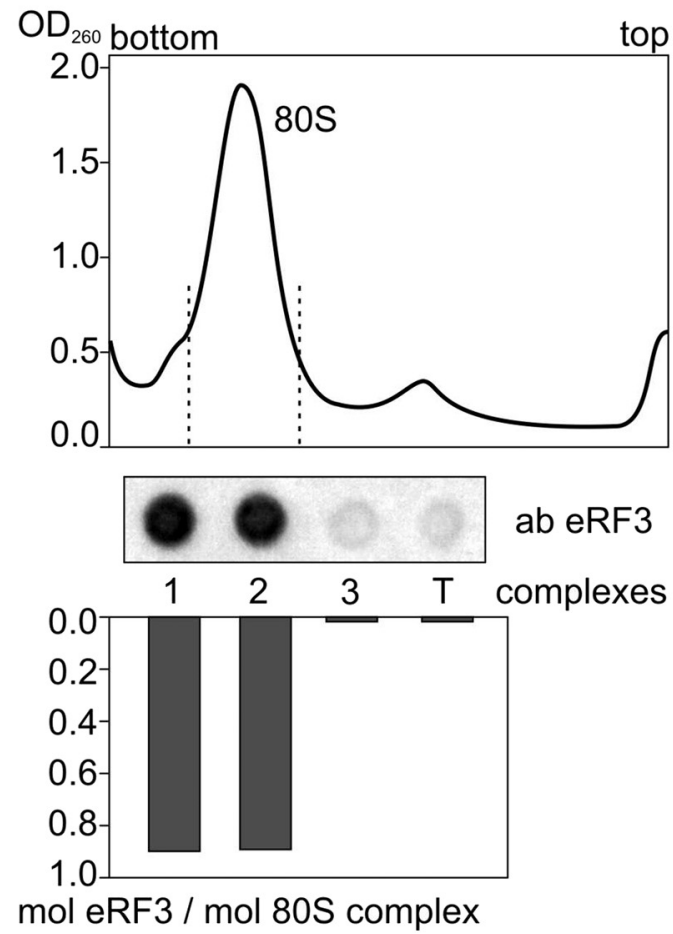

Fig. 1. Analysis of eRF3 binding levels in human $80 \mathrm{~S}$ translation termination complexes. (A) Types of complexes used. Note, in complex 2, GTP is converted to GDP by eRF3 GTPase activity, and Figure 1A shows a state after GTP hydrolysis, where eRF3•GDP has been suggested to remain bound to the ribosome [16]. (B) Determination of the eRF3 content by the means of dot blot assay applied to the purified complexes with subsequent estimation of eRF3 amounts by scanning of the respective signals displayed on the membrane with the use of a calibration curve obtained with definite amounts of eRF3 developed by the same assay. A typical profile of the sedimentation of $80 \mathrm{~S}$ complexes in the sucrose density gradient is shown, and its fraction taken for the dot blot assay is marked.

80S ribosome in simplified model systems and thereby enabling termination complexes formation. The increased $\mathrm{Mg}^{2+}$ concentration most likely affects structural flexibility of the complexes rather than the structures themselves, which is justified, in particular, by the good agreement of cross-linking data obtained at $10 \mathrm{mM} \mathrm{Mg}^{2+}$ [5-7] with cryo-EM structures of termination complexes [9-14]. Besides, no substantial differences have been found between the data on the cross-linking of mRNA analogues to the human ribosome at $13 \mathrm{mM}$ and $4 \mathrm{mM} \mathrm{Mg}^{2+}[32]$, which also supports the above statement. 


\section{A}
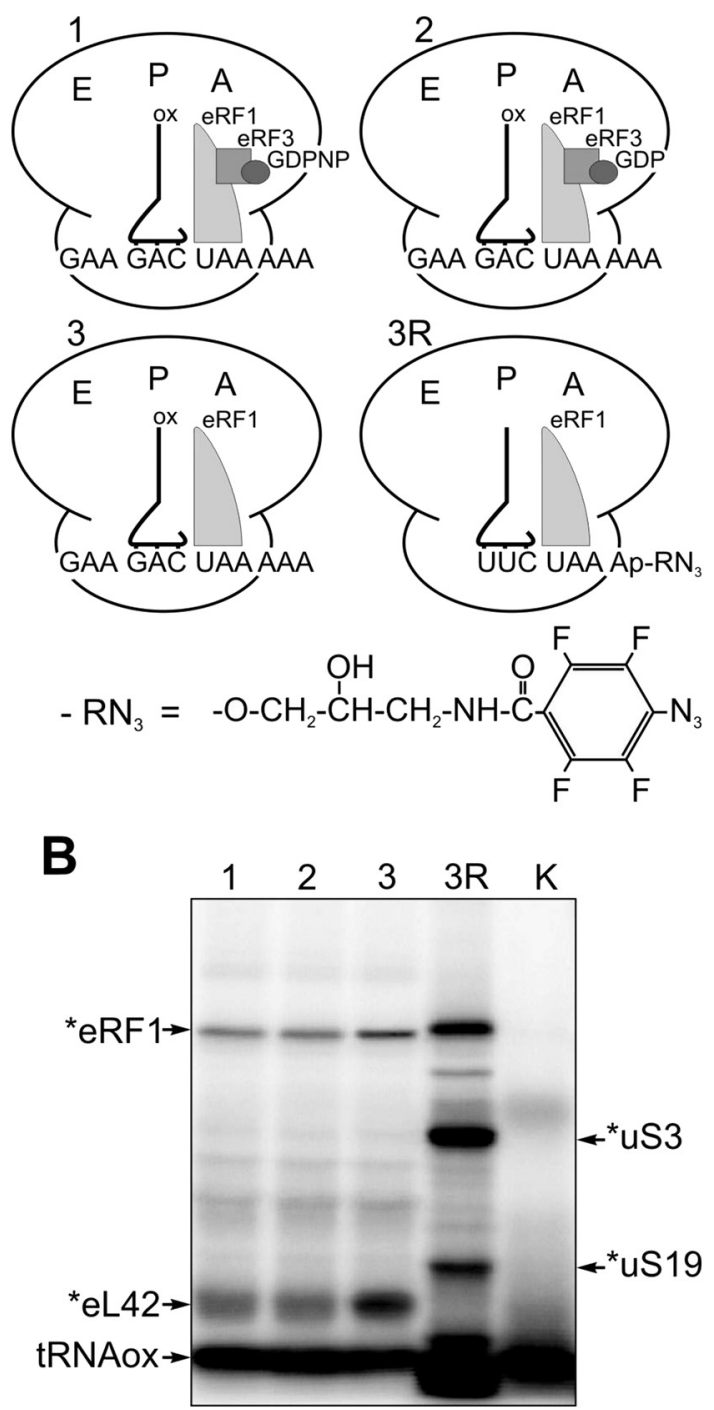

Fig. 2. Cross-linking of ${ }^{32} \mathrm{P}$-labeled tRNA $\mathrm{ox}_{\mathrm{Asp}}$ to proteins in the $80 \mathrm{~S}$ translation termination complexes. (A) Types of complexes used. (B) Autoradiogram of the gel after analysis of proteins cross-linked in the respective complexes. A band of cross-linked rp eL42 was identified according to the previous data [26]. Asterisks in the designations of protein bands indicate that these bands correspond to the cross-linked proteins. Lane $\mathrm{K}$, the binary mixture of tRNAox with eRF1 (without ribosomes).

The termination complexes assembled with unmodified tRNA ${ }^{\text {Phe }}$ and an appropriate unmodified short mRNA analogue were applied to figure out whether eRF3 remained bound to the 80S ribosome after the GTP hydrolysis (Fig. 1A). Similar complexes with mRNAox were used to study contacts of the $3^{\prime}$-terminus of stop signal with both ribosomal proteins and eRF1. To examine interactions between the 3 '-terminus of the P site tRNA and eRF1 at various translation termination steps, the complexes obtained with tRNA Asp (Fig. 2A) were employed. Complex $3 \mathrm{R}$ analogous to complex 3 contained the unmodified tRNA and an mRNA analogue bearing a photocross-linker at the 3 '-terminal phosphate of the stop signal (Fig. 2A). This complex was utilized to produce a reference cross-linked peptide resulting from $\mathrm{CNBr}$-induced cleavage of cross-linked eRF1 since the site of the mRNA analogue attachment to eRF1 in this complex had been identified earlier [7].

To examine eRF3 content in complexes 1 and 2 (Fig. 1A), we applied a dot blot assay with the use of anti-eRF3 antibodies (Fig. 1B). Ternary complex of $80 \mathrm{~S}$ ribosomes with the P site tRNA and mRNA analogue containing no release factors (complex T) and complex 3 without eRF3 served as negative controls. Quantification of the results presented in Fig. 1B clearly showed that complexes 1 and 2 contained practically equal amounts of eRF3 that dramatically exceeded the respective background values in complexes 3 and T. The similarity in amounts of eRF3 in complexes 1 and 2 was considered as functionally significant because the binding of both eRF1 and eRF3 to the ribosome in these complexes was mainly specific, i.e., strongly dependent on the presence of mRNA stop codon at the A site and of tRNA at the P site (see Supplementary information and Fig. S1). Thus, the obtained results provided evidence that eRF3 remained bound to the ribosome in complex 2, in which GTP was allowed to be hydrolyzed, in accordance with our earlier observation of pronounced structural changes in the ribosomal GTPase-associated center in this complex [16].

Cross-linking procedure applied to termination complexes with tRNA $A_{\mathrm{ox}}^{\text {Asp }}$ or mRNAox was analogous to that employed in the previous reports $[26,27,33]$. It included two steps, first, formation of Schiff bases between the aldehyde groups and lysine or arginine residues of proteins interacting with 3 '-terminus of tRNA or stop signal in the termination complexes, and second, reduction of these Schiff bases by sodium cyanoborohydride to obtain stable near-zero-length cross-links.

\subsection{Mapping of the cross-linking site of the $P$ site $t R N A_{o x}^{A s p} 3^{\prime}$-terminus on eRF1}

Since positioning of the eRF1 M domain and its crucially important tripeptide GGQ with respect to the ribosomal PTC undergoes considerable alterations in the course of termination, we performed a comparative analysis of the eRF1 contacts with the 3 '-terminus of the P site tRNA in the model termination complexes 1-3 assembled with RNA $_{\mathrm{ox}}^{\text {Asp }}$ (Fig. 2A). The cross-links generated by tRNA ${ }_{\text {ox }}^{\text {Asp }}$ in these complexes have been already analyzed [31] to test its capability of cross-linking to eRF1 and to the rp eL42 (formerly called as rp L36AL) that had been found modified with tRNA ${ }^{\text {Asp }}$ ox in the P/E hybrid state [26]. It has been shown that the cross-linking patterns along with the lower band referred to cross-linked rp eL42 contained an upper band corresponding to a product with molecular mass $\approx 85 \mathrm{kDa}$. The occurrence of eRF1 moiety in the upper band has been proven by mass-spectrometry analysis and immunoblotting assay. The apparent molecular mass of this product has allowed the suggestion that it was formed due to the cross-linking of tRNA ${ }^{\text {Asp }}$ ox to both rp eL42 and eRF1, which involved two aldehyde groups of the 3 '-terminal adenosine [31]. To determine more precisely whether the one tRNA ${ }_{\text {ox }}^{\text {Asp }}$ molecule could be crosslinked simultaneously to the both proteins, we further analyzed crosslinks generated by tRNA ${ }^{\mathrm{Asp}}{ }_{\text {ox }}$ in complexes 1-3 by 1D SDS-PAGE after preliminary hydrolysis of the tRNA moiety with RNase T1, which left labeled trinucleotide $\mathrm{C}\left[{ }^{32} \mathrm{P}\right] \mathrm{pCpA}$ attached to the protein(s). In parallel, cross-linking of an aryl azide-derivatized heptameric mRNA analogue in complex 3R was also performed to produce reference cross-links identified earlier [7]. Fig. 2B shows that cross-linking patterns for complexes 1-3 are similar. The patterns contain a band in the upper part of the gel, which corresponds to a product with electrophoretic mobility almost identical to the reference mRNA analogue cross-link to eRF1, indicating that the upper band represents eRF1 cross-linked to $C\left[{ }^{32} \mathrm{P}\right]$ pCpA fragment (Fig. 2B, lanes 1-3 and 3R). Minor distinction between the mobilities of eRF1 cross-linked to the above tri- and heptaribonucleotide fragments is expectable because molecular masses of these fragments differ. Considering that in termination complexes 1-3 tRNA $^{\text {Asp }}$ ox could exist in both $\mathrm{P} / \mathrm{P}$ and $\mathrm{P} / \mathrm{E}$ states, we can definitely conclude that tRNA ${ }^{\mathrm{Asp}}$ ox being in the $\mathrm{P} / \mathrm{P}$ state is able to cross-link only to eRF1, while in the $\mathrm{P} / \mathrm{E}$ hybrid state it cross-links to rp eL42. The evidence for the specificity of the interaction of tRNA ${ }^{\text {Asp }}{ }_{\text {ox }}$ with eRF1 in termination complexes 1-3 is the absence of eRF1-tRNA ${ }^{\text {Asp }}$ ox cross-link in the respective binary mixture lacking the ribosomes (Fig. 2B, lane $\mathrm{K}$ ). The strong dependence of the cross-link yield on the existence of the codon-anticodon interaction at the $\mathrm{P}$ site and on the presence of the stop codon at the A site also indicates high specificity of this interaction 


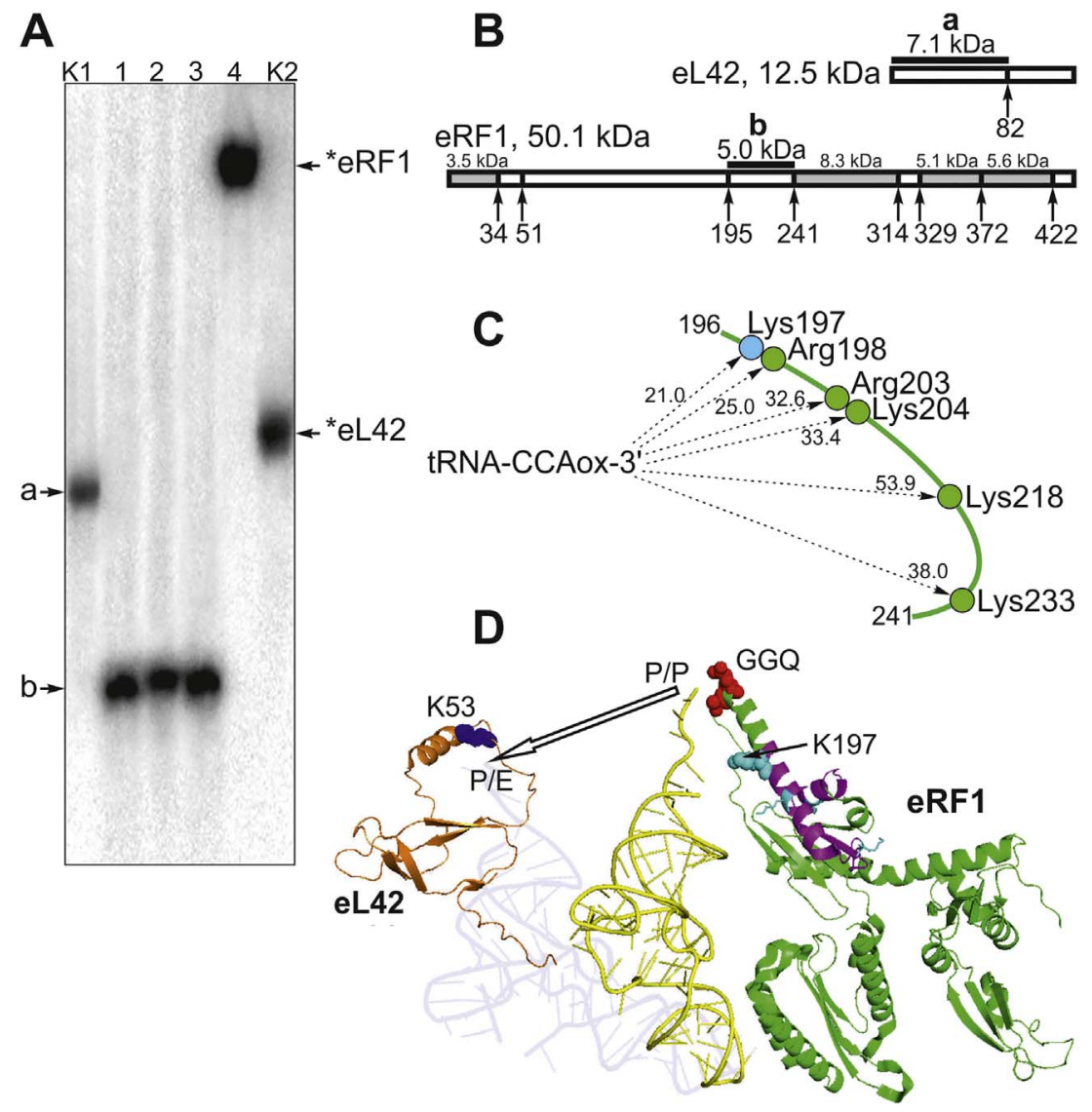

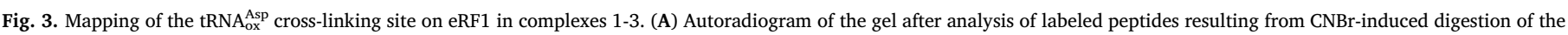

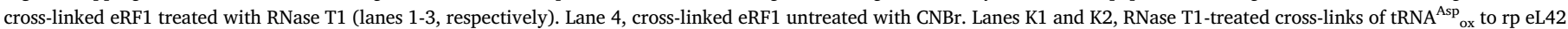

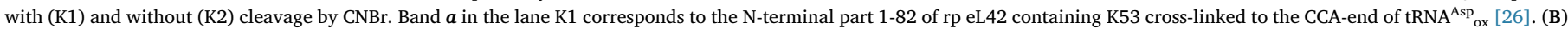

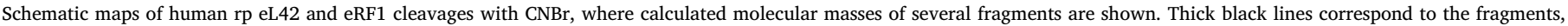

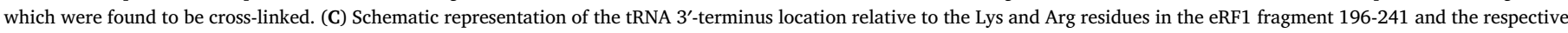

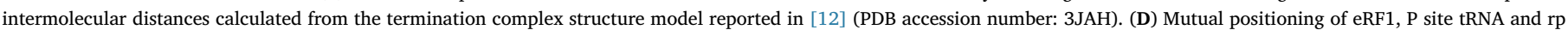

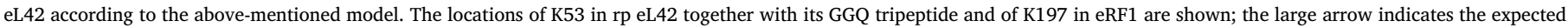
direction of movement of the P site tRNA $3^{\prime}$-terminus from the $\mathrm{P} / \mathrm{P}$ to the $\mathrm{P} / \mathrm{E}$ state.

(see Supplementary information and Figure S2).

To map the cross-link on eRF1, the modified factor, in which the cross-linked tRNA was hydrolyzed with RNase T1, was purified by 1D SDS PAGE and cleaved at methionine residues by $\mathrm{CNBr}$ with the subsequent separation of the resulting products by tris-tricine SDSPAGE. Fig. 3A shows that cross-linking patterns are very similar for all three model termination complexes. The patterns contain a single band $\boldsymbol{b}$ in the lower part of the gel, which corresponds to the labeled eRF1 fragment with molecular mass about $5 \mathrm{kDa}$ (after subtracting of the mass of the cross-linked trinucleotide (CA), and the cross-linking yields to this fragment are almost the same in all three complexes. To facilitate evaluation of the mass of the eRF1 cross-linked peptide, we resolved on the same gel the cross-link of tRNA Asp to rp eL42 sequentially treated with RNase $\mathrm{T} 1$ and $\mathrm{CNBr}$, and the same cross-link untreated with $\mathrm{CNBr}$ as two reference modified peptides. The analysis of schematic map of CNBr-induced cleavage of eRF1 (Fig. 3B) revealed four candidate fragments that might contain the cross-linking site, namely those whose masses were equal or close to $5 \mathrm{kDa}(196-241,329-372$ and 372-422) as well as peptide 2-34 (3.5 $\mathrm{kDa})$ that might be also taken into consideration. Based on the available structural data, we excluded three out of four candidate fragments. In particular, peptide 2-34 is arranged in the termination complexes close to mRNA stop signal [6], i.e., it is located in a vicinity of the decoding area, which can never be near the PTC since these regions in the ribosome are separated by a distance of 70-80 $\AA$ (the distance between tRNA anticodon and 3'-terminus). Similarly, fragments $329-372$ and $372-422$ are in the C domain of eRF1, which is oriented away from the PTC region in all available cryo-EM structures of eukaryotic termination complexes [9-14]. Thus, we mapped our cross-link to the M domain fragment 196-241. This fragment resides nearby the GGQ tripeptide (positions 183-185) and among Lys and Arg residues of the fragment, Lys197 is the closest to the $3^{\prime}$-terminus of the $\mathrm{P}$ site tRNA according to cryo-EM structural model of the termination complex mimicking a state after GTP hydrolysis immediately prior to the peptide release [12] (Fig. 3C). Therefore, we consider Lys197 as the most likely target of cross-linking of $\mathrm{tRNA}^{\mathrm{Asp}}$ ox in all three model termination complexes.

\subsection{Identification of ribosomal proteins cross-linked to an $m R N A$ analogue with oxidized ribose in the $4^{\text {th }}$ position of stop signal}

Earlier, we have successfully applied 3'-dialdehyde derivatives of oligoribonucleotides for the examination of the protein environment of mRNA in the human ribosomal complexes containing deacylated tRNA at the $\mathrm{P}$ site [33]. The results of our earlier cross-linking studies [32,34-36] have shown that the environment of mRNA on the human ribosome does not depend on the presence of a peptidyl moiety at the 3 '-end of the P site tRNA. These data justify the applicability of complexes with eRF1•eRF3•GMPPNP and deacylated tRNA at the P site for investigation of mRNA positioning relative to the ribosome and eRF1 at the translation termination step associated with stop codon recognition by eRF1. Here, to explore the protein environment of mRNA in termination complexes 1-3 (Fig. 4A), we used mRNAox with 


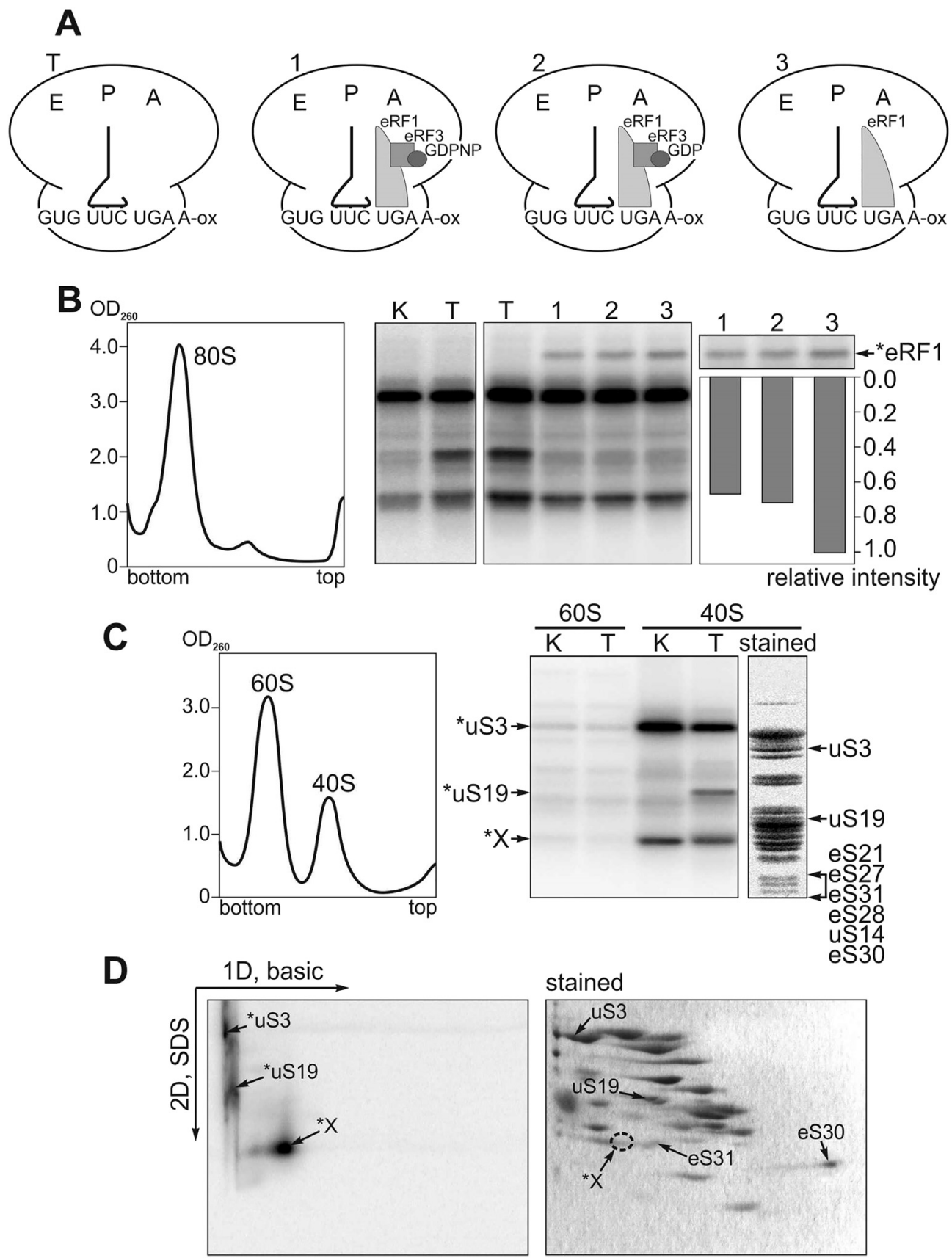

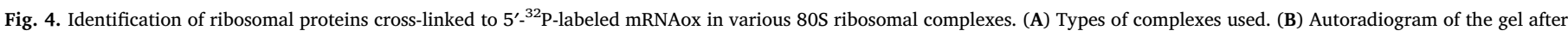

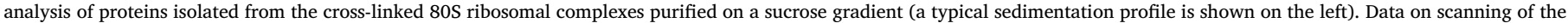

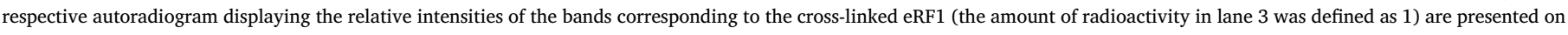

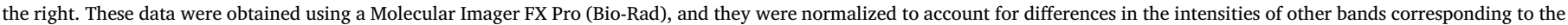

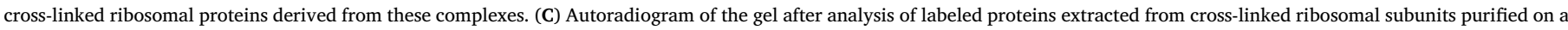

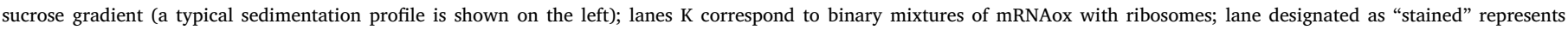

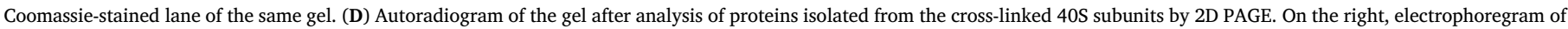

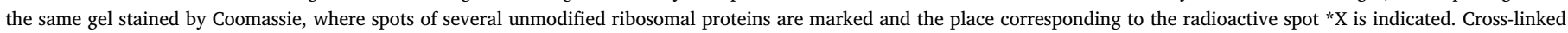
proteins corresponding to radioactive spots are marked with asterisks in the autoradiogram. The radioactive spot * $\mathrm{X}$ is identified here as cross-linked rp eS30.

$3^{\prime}$-terminal oxidized ribose in $4^{\text {th }}$ position of stop signal. In parallel, we studied also factor-free complex of mRNAox with 80S ribosomes and tRNA at the $\mathrm{P}$ site (complex T, Fig. 4A) and the binary mixture $\mathrm{K}$ without tRNA (not shown in Fig. 4A). The 1D SDS-PAGE analysis revealed cross-linked eRF1 in all termination complexes, and the yields of mRNAox cross-linking to eRF1 in complexes 1 and 2 were noticeably lower than that in complex 3 (Fig. 4B).

Several bands of cross-linked ribosomal proteins were observed, and an intensity of some of them depended on the complex type. The analysis of proteins from ribosomal subunits obtained from the crosslinked $80 \mathrm{~S}$ ribosomal complexes $\mathrm{T}$ and $\mathrm{K}$ showed that all cross-linked proteins belonged to the 40S subunit (Fig. 4C). Our previous data [33] on ribosomal proteins cross-linked to similar RNA derivatives enabled us to identify the upper and middle bands as cross-linked rp uS3 and rp uS19 (S15 according to the previous nomenclature), respectively. As expected, cross-linking to rp uS3 was effective and almost independent on the complex type, and cross-linking to rp uS19 completely depended on the presence of tRNA that fixed mRNAox on the ribosome so that its 
3 '-terminal oxidized nucleotide occurred at the decoding site region where rp uS19 is located [36-38]. Cross-linking of mRNAox to rp uS19 was quenched by eRF1 in all termination complexes (Fig. 4B, lanes 1-3), which was consistent with the earlier data obtained with mRNA analogues containing 4-thiouridine in the stop signal [17].

Identification of the lower radioactive band was more complicated; taking into account retardation of protein electrophoretic mobility caused by the cross-linked RNA moiety, one could consider a set of candidate cross-linked ribosomal proteins including eS21, eS27, eS28, uS14, eS30 and eS31 (Fig. 4C). One of these proteins, rp eS30, has been identified as a minor target for cross-linking of photoactivatable mRNA analogues whose nucleotide bearing an aryl azide cross-linker was in the A site bound codon or immediately $3^{\prime}$ of it [29]. Later, neighborhood of this protein with mRNA $3^{\prime}$ of the A site codon has been confirmed by cryo-EM [39]. According to structural data, eS21, eS27, eS28 and uS14 proteins are very unlikely targets for cross-linking due to their location far away from the ribosomal decoding site (e.g., see [40-43]). To confirm that rp eS30 was indeed a target for cross-linking of mRNAox, we carried out 2D PAGE analysis of ribosomal proteins (Fig. 4D). In the system applied here, radioactive spot of a modified protein is shifted mainly to the left and slightly upwards as compared to the spot of the respective unmodified protein in the stained gel [36]. The results of analysis show that the location of the radioactive spot in the gel corresponds to that expected for cross-linked rp eS30 and that radioactive spot is in an immediate vicinity of the stained rp eS31 spot. Therefore, we excluded rp eS31 from candidate proteins based on the well-known fact that the cross-linked oligoribonucleotide moiety strongly retards migration of the modified protein in the first dimension of 2D PAGE, which is clearly seen with the cross-linked rp uS19 (Fig. 4D). Thus, proteins eS30 and uS19 residing at the ribosomal decoding site contact ribose in the $4^{\text {th }}$ position of mRNA stop signal in the ternary complex of $80 \mathrm{~S}$ ribosomes that corresponds to the translation pre-termination step occurring prior to the stop codon decoding by release factors.

\subsection{Fragments of rp eS3O and eRF1 involved in the interactions with $m R N A$ stop signal in different complexes}

We mapped rp eS30 and eRF1 regions cross-linked to mRNAox using specific CNBr-induced cleavage by analogy with our previous studies (see [44] and refs therein). The cleavage of rp eS30 cross-linked to mRNAox resulted in the formation of two labeled fragments $\boldsymbol{a}$ and $\boldsymbol{b}$ (Fig. 5A), which corresponded to the $\mathrm{N}$ - and C-terminal parts of the protein, respectively, in accordance with the single internal methionine residue in human rp eS30 (Fig. 5B). The obtained results indicated that modification of the smaller fragment $\boldsymbol{b}$ was unspecific since its yield was similar in all cases including the binary mixture of mRNAox with ribosomes. On the contrary, cross-linking to the larger fragment $\boldsymbol{a}$ was specific because it was observed only in the ribosomal complexes formed with tRNA cognate to the codon targeted to the P site. In fragment $\boldsymbol{a}$, the most probable cross-linking targets were Lys and Arg residues in positions 1 and 8 , respectively. The first residue of rp eS30 is unresolved in cryo-EM models of both the mRNA- and tRNA-bound 80S ribosome with vacant A site [39] and the termination complex mimicking a state after GTP hydrolysis immediately prior to the peptide release [12]. As far as Arg8, it is at a distance of $\approx 22-23 \AA$ from ribose of nucleotide immediately $3^{\prime}$ of the A site-bound codon in these models (Fig. 5C, D). All other amino acid residues capable of cross-linking to mRNAox are located at such distances from this ribose that exclude their interaction with it. Considering that the closest resolved residue of rp eS30, Phe in position 3, is located at a distance about $20 \AA$ from the ribose of nucleotide in the $4^{\text {th }}$ position of the stop signal [12], one can assume that Lys1 is a more preferable target for the mRNAox crosslinking because it seems to be closer to this ribose than Arg8. In all termination complexes, the yield of the fragment $\boldsymbol{a}$ was considerably lower than that in the ternary complex T (Fig. 5A, compare lanes 1-3
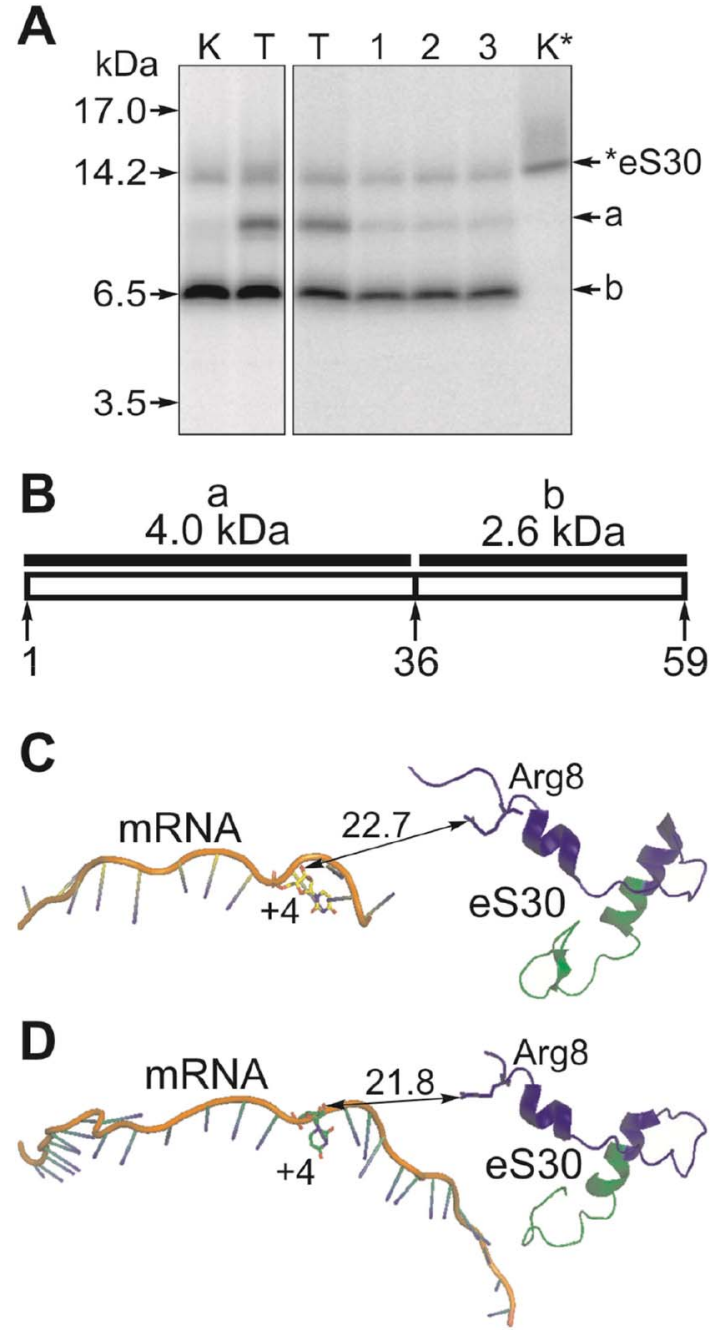

Fig. 5. Identification of rp eS30 fragments cross-linked to mRNAox in various $80 \mathrm{~S}$ ribosomal complexes (for details, see Fig. 4A). (A) Autoradiograms of the gels after tristricine SDS-PAGE analysis of labeled peptides resulting from CNBr-induced digestion of rp eS30 cross-linked in complexes 1-3, T or in the binary mixture of mRNAox with 80S ribosomes (lane $\mathrm{K}$ ); lane $\mathrm{K}^{*}$ corresponds to cross-linked rp eS30 untreated with CNBr. Positions of bands corresponding to molecular mass markers are given on the left. (B) Schematic map of the CNBr-induced cleavage of human rp eS30, the calculated fragment masses are indicated above the diagram. Note that molecular mass of mRNAox crosslinked to rp eS30 is $3.4 \mathrm{kDa}$. (C and D) Locations of ribose of the nucleotide immediately $3^{\prime}$ of the A site-bound codon relative to Arg8 of rp eS30 according to [12] (see the legend to Fig. 3C) and [39] (PDB accession number: 4CXC), respectively.

and $\mathrm{T}$ ). The only component that was absent in complex $\mathrm{T}$ but was present in all three termination complexes was eRF1. Thus, it was eRF1 that shielded the N-terminal part of rp eS30 together with rp uS19 (see above) from the cross-linking to stop signal.

Earlier, we have applied site-directed cross-linking with the use of aryl azide-derivatized mRNA analogues [6,7] to examine positioning of stop signal relatively to eRF1 peptides in complexes resembling complex 3 (Fig. 4A). Here, we identified eRF1 sites cross-linked to 3'terminal oxidized ribose in the $4^{\text {th }}$ position of the stop signal in termination complexes 1 and 2 to obtain information on eRF1-stop signal contacts at the respective termination steps. We also clarified whether eRF3 occurrence and GTP hydrolysis change the location of eRF1 relative to stop signal as compared to that in complex 3R (Fig. 2A) studied previously, where mRNA analogue cross-linked to Val66 of eRF1 [7]. In all three termination complexes, cross-links were found to reside within eRF1 fragment 52-195 (Fig. 6A, B and C) in accordance with our previous results on mapping of the cross-links of photoactivated mRNA analogues on eRF1 produced in type 3 complexes $[6,7]$. 

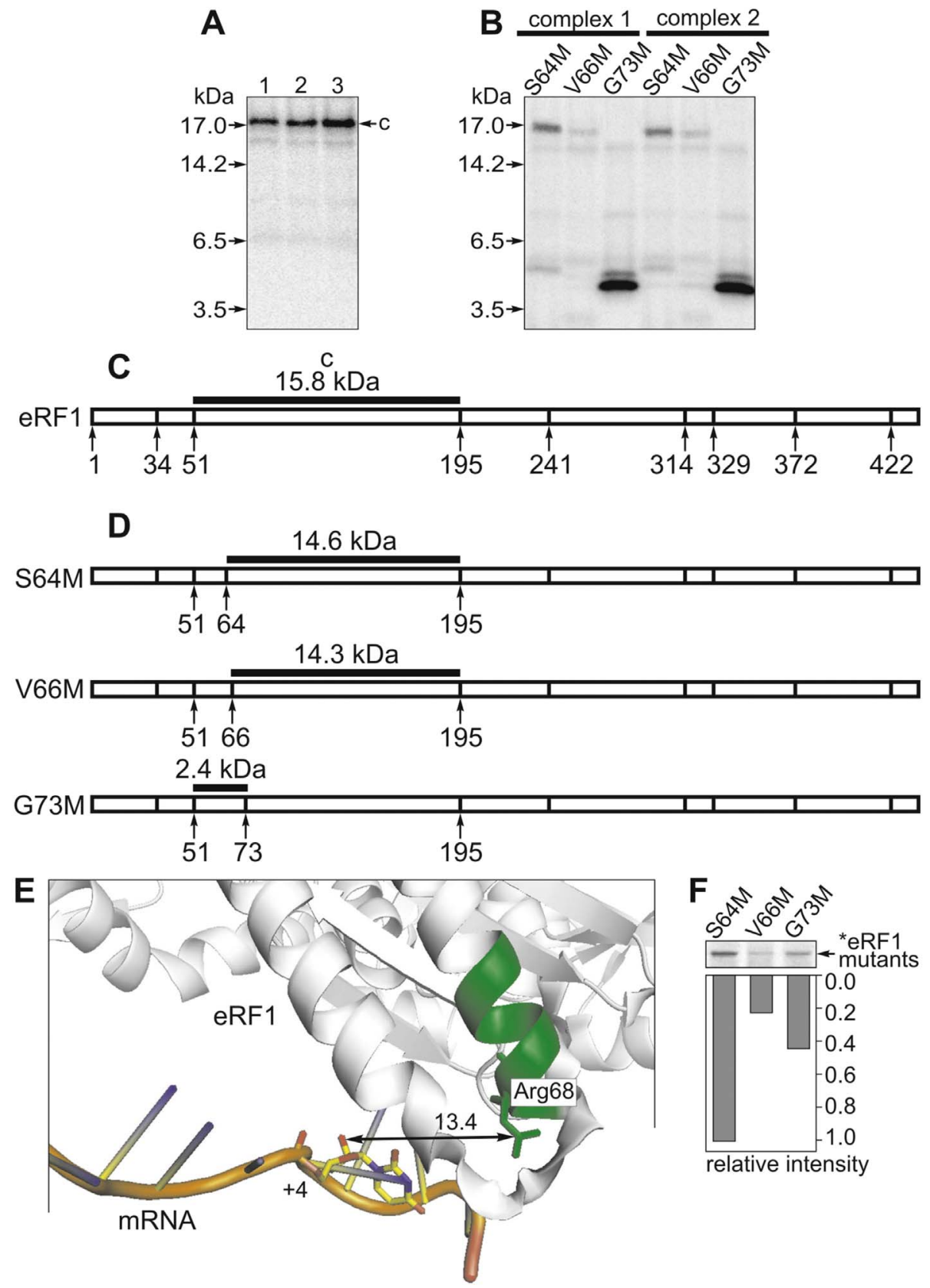

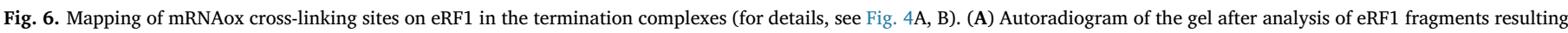

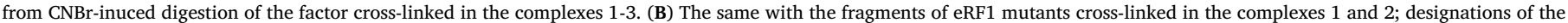

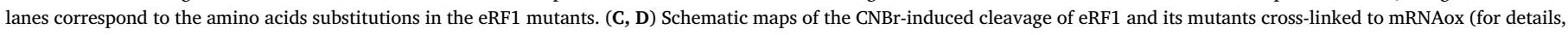

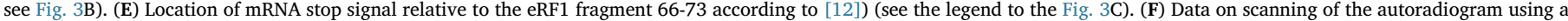

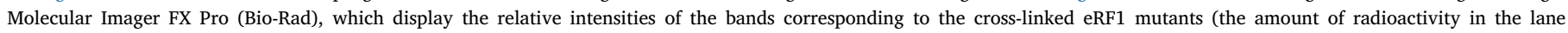
corresponding to mutant S64M was defined as 1).

To map the cross-links in complexes 1 and 2, we used eRF1 mutants containing single amino acid substitutions for methionine (S64M, V66M and G73M) to introduce artificial CNBr cleavage sites into the eRF1 region adjoining to the TASNIKS motif (57-63) essential for stop codon recognition. This type of mutants has been already utilized for the identification of stop codon recognition site in eRF1 [5-7]. CNBrinduced cleavage of the eRF1 mutants cross-linked to mRNAox (Fig. 6B, $\mathrm{C}$ and $\mathrm{D}$ ) revealed that the cross-link was located on the C-terminal side of position 66 and on the N-terminal side of position 73, i.e., within fragment 67-73 in both examined complexes 1 and 2. The cross-link obviously involves Arg68 located at a distance of about $13 \AA$ from the ribose of nucleotide in the $4^{\text {th }}$ position of the stop signal (Fig. $6 \mathrm{E}$ ) according to the cryo-EM model of the termination complex [12], since it is the only residue capable of cross-linking to mRNAox within fragment 67-73. A significantly lower cross-link yield with eRF1 mutant V66M compared to those observed with other mutants (Fig. 6B, F) is consistent with earlier data on the reduced activity of the V66M mutant in relation to the UGA stop codon [5], confirming the importance of Val66 for the interaction of the N-terminal domain of eRF1 with this stop codon.

\section{Discussion}

In this study, the analysis of eRF3 content in purified model ribosomal complexes mimicking various translation termination steps showed for the first time that eRF3 does not leave the ribosome after 
GTP hydrolysis. Applying site-directed cross-linking with the use of tRNA and mRNA analogues bearing an oxidized ribose, we determined locations of the 3 -terminus of the P site tRNA relative to the eRF1 M domain and of the mRNA stop signal toward the eRF1 N domain and the ribosomal decoding site. Our results point out that the positioning of the mRNA stop signal is similar at all translation termination steps from stop codon recognition up to post-termination pre-recycling state. We realize that the complex with eRF1•eRF3•GMPPNP and deacylated $\mathrm{P}$ site tRNA has limited functional relevance when contacts of the factors with $3^{\prime}$-terminus of the P site tRNA are studied since actually the pretermination ribosome contains peptidyl-tRNA at the P site. However, the application of tRNAox here allowed us to evaluate the role of the tRNA peptidyl moiety in the arrangement of eRF1 in the pre-termination complex before GTP hydrolysis in addition to obtaining the data on similar locations of the 3 -terminus of the P site tRNA at the steps following the recognition of the mRNA stop codon up to post-termination pre-recycling state. Our findings provide new information on contacts of the key structural elements of eRF1, tRNA and mRNA at the different termination states of $80 \mathrm{~S}$ ribosomes, including a posttermination complex containing eRF3•GDP, which has not yet been studied by cryo-EM. The obtained results highlight a new specific feature of termination complexes, which is manifested in shielding of the N-terminal part of $\mathrm{rp}$ eS30 from interaction with the backbone of stop signal observed with a pre-termination ribosome free of eRFs. The C-terminal part of the protein is capable of cross-linking to an oligoribonucleotide derivative bearing an oxidized ribose independently on the presence of tRNA.

\subsection{GTP hydrolysis, eRF3 dissociation and positioning of the 3'-terminus of the $P$ site tRNA in termination complexes}

Here we found that binding level of eRF3 in model termination complexes obtained with deacylated P site tRNA hardly depends on whether they are formed with GTP (complex 2, Fig. 1A) or its nonhydrolysable analogue GMPPNP (complex 1, Fig. 1A). Earlier, by means of chemical footprinting of rRNA in model complexes analogous to those used in this study, we have shown that GTP hydrolysis in a complex type 2 is displayed by rearrangements in 28S rRNA helix 44 in the ribosomal GTPase-associated center [16]. The restructuring of this center has been clearly detectable in complex type 2 but not in complex types 1 or 3 . Moreover, the same sets of rRNA nucleotides protected from chemical attack in complex types 1 and 2 have pointed out that eRF3 does not dissociate from the ribosome after GTP hydrolysis [16]. This possibility (together with an alternative one concerning dissociation of eRF3•GDP) has been considered earlier [15]. It has been hypothesized that eRF3-GDP-bound post-termination complexes can productively interact with $A B C E 1$, which in turn has led to a speculation that eRF3 release is mediated by ABCE1 [9] whose binding site on the ribosome overlaps with that of eRF3 [45]. In contrast, eRF3 dissociation from the ribosome immediately after GTP hydrolysis before ABCE1 binding has been suggested [11]. The results obtained in the present study provide the first direct evidence that eRF3 remains bound at the termination complex after GTP hydrolysis and peptide release.

The rRNA chemical footprinting data have shown that in model complexes similar to complexes 1-3 (Fig. 1A) eRF1 binding site is stretched to the PTC region where the $3^{\prime}$-termini of the A- and P-site tRNAs are accommodated [16]. Here, we found that the 3 '-terminus of the P site tRNA actually contacts eRF1 in these complexes. Similar cross-linking patterns obtained with complexes 2 and 3 imply that positioning of eRF1 relative to the tRNA 3 '-terminus does not change after eRF3 dissociation. Quite unexpectedly, we revealed the same tRNA-eRF1 contact in the complex 1, although cryo-EM data indicate that before GTP hydrolysis the GGQ tripeptide of eRF1 is located far away from the PTC [9-11], and biochemical data showed that the ester bond of the $\mathrm{P}$ site peptidyl-tRNA in the complexes obtained with GMPPNP is accessible for puromycin [46]. It is obvious that this discrepancy is associated with the different tRNA forms bound at the P-site; complex 1 employed in this study comprised deacylated tRNA, whereas pre-termination complexes mentioned above [9-11,46] contained peptidyl-tRNA. Thus, we conclude that, in agreement with suggestions made in our previous report [16], the GGQ fragment of eRF1 can reach the PTC region and contact the tRNA 3 '-terminus in the complex with GMPPNP and deacylated P site tRNA. This implies that it is peptidyl moiety of the P site tRNA that makes the PTC inaccessible for eRF1 at the stop codon recognition step preceding GTP hydrolysis.

Analysis of the structure of the complex mimicking termination state after GTP hydrolysis prior to peptide release [12] showed that Lys197, which interacts with the 3 '-terminus of the P site tRNA according to the results of this study, is located at a distance of $21 \AA$ from the 3'-terminus of peptidyl-tRNA (Fig. 3C). This distance seems to be too large to allow the formation of zero-length cross-links. We believe that the interaction between eRF1 and the 3 '-terminus of the deacylated P site tRNA in complexes 1-3 takes place due to the flexibility of the latter, which also enables oscillations of the $\mathrm{P}$ site tRNA between two alternative states, $\mathrm{P} / \mathrm{P}$ and $\mathrm{P} / \mathrm{E}$, to occur. The $\mathrm{P} / \mathrm{P}$ state is responsible for the contact of the $3^{\prime}$-terminus of the deacylated tRNA with eRF1 in the PTC region, and the P/E state provides its interaction with rp eL42 (Fig. 3D) in agreement with an earlier suggestion concerning complexes resembling complex $\mathrm{T}$ (see Fig. 1A) and that with tRNA molecule at the A site [26].

Surprisingly, rp eL42, like eRF1, contains a GGQ tripeptide located in close proximity to K53, the rp eL42 site contacting 3 '-CCA-end of the $\mathrm{P}$ site tRNA [26], and it is the only mammalian ribosomal protein comprising this motif. As the eRF1 GGQ motif is responsible for triggering hydrolysis of peptidyl-tRNA in the ribosomal PTC site, we assume that the location of rp eL42 GGQ tripeptide near the 3 '-terminus of the P site tRNA is not a mere coincidence and it may reflect a possible role of this unique for ribosomal proteins motif in the translation process. In particular, rp eL42 GGQ motif might somehow be involved in promoting peptide release, and examination of this issue is an attractive frontier of further investigations.

\subsection{Contacts of stop signal backbone with ribosome and eRF1 in the course of termination}

Since termination step following GTP hydrolysis and peptide release but preceding eRF3 dissociation (corresponding to complex 2 in this study) has not yet been investigated, our study represents the first direct data on the positioning of mRNA stop signal with respect to eRF1 and the ribosome at this step. We found that the cross-link of dialdehyde group at the ribose of nucleotide in the $4^{\text {th }}$ stop signal position occurs within the $\mathrm{N}$ domain fragment 67-73 next to the TASNIKS motif at its C-terminal side. Besides, we showed that eRF1 shields the N-terminal fragment of rp eS30 along with rp uS19 whose Cterminal tail resides in ribosomal decoding site $[47,48]$ from crosslinking to this dialdehyde group. The shielding effect of eRF1 on crosslinking of stop codon to rp uS19 has been observed earlier [17]. A similar effect has been shown to be provided by the A site-bound tRNA that blocked the modification of this protein with mRNA analogue bearing 3 '-oxidized ribose in the same position as mRNAox used in this study [33]. Cross-linking of mRNA nucleotide immediately downstream of the A site codon to N-terminal part of rp eS30 is consistent with known data on the location of this protein fragment at the binding site of mRNA $3^{\prime}$ of the A site-bound codon $[29,39]$ and with its probable implication in the decoding process during elongation [48]. Our finding that N-terminal part of rp eS30 contacting mRNA in a pre-termination complex ready to bind release factors at the A site becomes shielded when eRF1 is bound at the A site implies that this rp eS30 part likely interacts with eRF1 in the course of translation termination. However, the distance between ribose of nucleotide in the $4^{\text {th }}$ stop signal position and one of the proposed targets for modification at the N-terminal fragment of rp eS30 evaluated from the cryo-EM models (Fig. 5C, D) 

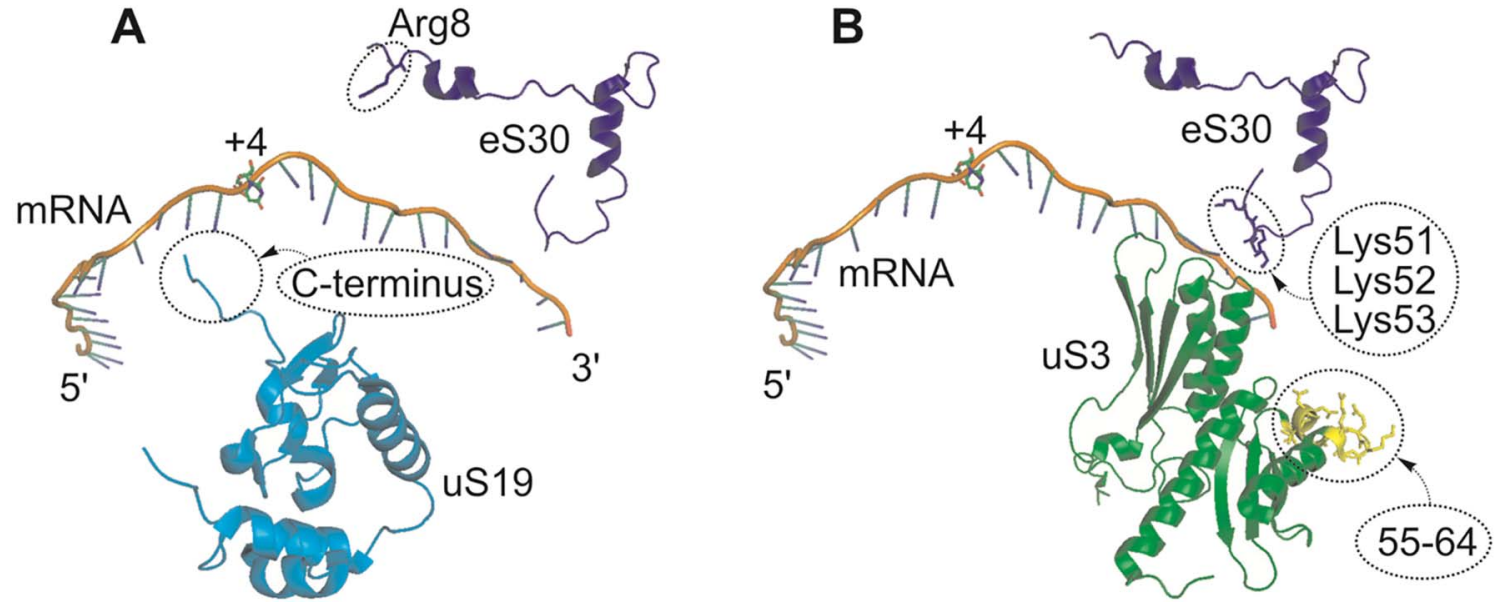

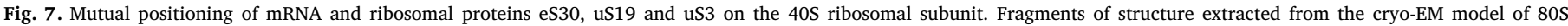
termination complex reported in [12] (see a legend to Fig. 3C) and corresponding to the ribosomal decoding region (A) and to the mRNA entry channel (B).

seems too large for zero-length cross-link formation. Apparently, the respective cross-linking in complex $\mathrm{T}$ (Fig. 4A) occurred because stop codon was not fixed by interaction with eRF1 at the A site. In general, we conclude that the above shielding effects are specific features of ribosomal complexes with A site occupied by eRF1 or tRNA that distinguish these complexes from elongation and pre-termination ribosomes with empty A site, where the A site-bound codon along with nucleotide adjacent to it is able to interact with rp uS19 and rp eS30 (Fig. 7A).

Cryo-EM data on post-termination complex containing ABCE1 instead of eRF3 have suggested that the A site stop codon is disengaged from the N-terminal domain of eRF1 [11]. Our results demonstrate that pattern of the cross-linking of oxidized nucleotide in the $4^{\text {th }}$ stop signal position in eRF1 is the same in all three examined termination states (Fig. 5A). However, scan data obtained from three independent experiments show that the intensities of radioactive bands corresponding to the cross-linked eRF1 in eRF3-containing complexes 1 and 2 are reduced by approximately $30 \%$ as compared to that with complex 3 (Fig. 4B). This observation indicates that eRF3 dissociation somewhat changes the location of the eRF1 N-terminal domain with respect to mRNA stop signal in the post-termination complex, making its contact with the ribose in the $4^{\text {th }}$ stop signal position tighter than in the eRF3containing complexes. Nevertheless, our results indicate that positioning of stop signal towards the $\mathrm{N}$ domain of eRF1 in general does not considerably change during translation termination. In all eRF1-containing complexes, the $\mathrm{N}$-terminal part of rp eS30 is shielded by eRF1 from the interaction with the ribose of nucleotide adjacent to stop codon, which takes place in pre-termination ribosomal complexes free of eRFs. Subsequent disengagement of the A site stop codon from the Nterminal domain of eRF1 may occur upon ABCE1 binding, since there is no need for the interaction of stop codon with eRF1 on following posttermination stages, in accordance with the above-mentioned suggestion [11].

Application of a 3 '-dialdehyde oligoribonucleotide derivative containing stop signal allowed us to reveal unseen earlier cross-link of the C-terminal fragment of rp eS30 to short single stranded RNA derivative, which took place even in the binary mixture of the derivative with $80 \mathrm{~S}$ ribosomes. In this mixture, oligoribonucleotide derivative did not form tight complex with the ribosome because it could not be placed in the ribosomal mRNA binding site in the absence of tRNA, which would direct the respective oligoribonucleotide triplet to the $\mathrm{P}$ site. Thus, mRNAox used in this study cross-linked to the C-terminal fragment of rp eS30 away from the mRNA binding site and the cross-link most likely involved Lys residues in positions 51-53 of the protein. Recently, we have shown cross-link of this type for rp uS3 that was effectively modified with 3 '-oxidized derivatives of short unstructured RNAs via an exposed part of its $\mathrm{KH}$ domain located near the ribosome mRNA entry channel [33]. With mRNAox, the cross-linking to rp uS3 was also observed (Fig. 4B, C) and the yield of the cross-link to this protein was higher than that to rp eS30. The analysis of cryo-EM structures of termination complexes $[12,13]$ shows that the tripeptide $51-53$ of rp eS30 is indeed far away from ribose nucleotide in $4^{\text {th }}$ stop signal position (at a distance about $46-48 \AA$ ) and, consequently, it cannot be cross-linked to mRNAox bound at the mRNA binding site. Moreover, this tripeptide is located not far from rp uS3 fragment 55-64 implicated in the protein cross-linking to derivatives of short single-stranded RNAs in the region of the ribosome mRNA entry channel [33] (Fig. 7B), which enables RNA transiently bound to the KH domain of rp uS3 to reach the above rp eS30 peptide by its 3 '-terminus.

\section{Conclusions}

This study provides for the first time direct evidence that eRF3 can remain bound to the $80 \mathrm{~S}$ ribosomal termination complex after GTP hydrolysis and peptide release. Site-directed cross-linking with the use of tRNA and oligoribonucleotide derivatives bearing a dialdehyde group at the $3^{\prime}$-terminus enabled us to obtain a new information on contacts of the eRF1 M domain with the $3^{\prime}$-terminus of the P site tRNA in the PTC region and of mRNA stop signal with the eRF1 N domain during translation termination. Our findings demonstrate at the nucleotide-peptide resolution level that in the complexes with deacylated tRNA at the $\mathrm{P}$ site these contacts are similar from the stop codon recognition step up to the step after the eRF3 dissociation before ribosome recycling. Besides, our results highlight a role of the peptidyl moiety of the P site tRNA in preventing the binding of the eRF1 GGQ motif in the PTC region at the pre-termination step on which the stop codon recognition by eRF1 occurs. We also showed that eRF1 shields the N-terminal part of rp eS30 located in the mRNA binding center from the interaction with ribose of nucleotide in $4^{\text {th }}$ stop signal position, and revealed that the C-terminal part of rp eS30 resides nearby the mRNA entry channel. The finding that the 3 -terminus of the P site tRNA contacts both $\mathrm{M}$ domain of eRF1 at the PTC region and rp eL42 belonging to the $\mathrm{E}$ site indicates oscillations of deacylated tRNA between the $\mathrm{P} / \mathrm{P}$ and $\mathrm{P} / \mathrm{E}$ states during termination due to the flexibility of its free CCA terminus. These P site tRNA oscillations should be similar to those occurring when the A site is empty or occupied by a tRNA molecule. Overall, the results of this study fill several gaps in understanding of the sequence of events taking place in the course of translation termination in eukaryotes as well as of structural aspects of molecular mechanisms underlying these events, raising for all that issues, which still have to be elucidated. 


\section{Competing interests}

No competing interests are declared.

\section{Authors' contributions}

G.G.K. and C.H. planned and designed experiments; K.N.B. carried out experiments; L.Yu.F. prepared DNA constructs encoding for eRF1 and its mutants and eRF3 as well as the respective recombinant proteins; all authors were involved in analysis and discussions of the results obtained in this study; D.M.G., L.Yu.F. and G.G.K. wrote the paper.

\section{Transparency document}

The http://dx.doi.org/10.1016/j.bbagrm.2017.04.004 associated with this article can be found, in online version.

\section{Acknowledgements}

The study was supported under the grants from the Russian Foundation for Basic Research (14-04-00709 and 17-04-00609 to G.G.K.), SB RAS Complex scientific program, № II.2П/VI.57-3 (grant 0309-2015-0024 to G.G.K), the Presidium RAS Program "Molecular and Cell Biology" (grant 0103-2015-0138 to L.Yu.F.) and partially under State funded budget project (VI.57.1.2, 0309-2016-0001).

\section{Appendix A. Supplementary data}

Supplementary data to this article can be found online at http://dx. doi.org/10.1016/j.bbagrm.2017.04.004.

\section{References}

[1] L. Frolova, R.Y Tsivkovskii, G.F. Sivolobova, N.Y. Oparina, O.I. Serpinsky, V.M. Blinov, S.I. Tatkov, L. Kisselev, Mutations in the highly conserved GGQ motif of class-1 polypeptide release factors abolish ability of human eRF1 to trigger peptidyl-tRNA hydrolysis, RNA 5 (1999) 1014-1020.

[2] G. Bertram, H.A. Bell, D.W. Ritchie, G. Fullerton, I. Stansfield, Terminating eukaryote translation: domain 1 of release factor eRF1 functions in stop codon recognition, RNA 6 (2000) 1236-1247.

[3] H. Song, P. Mugnier, H.M. Webb, D.R. Evans, M.F. Tuite, B.A. Hemmings, D. Barford, The crystal structure of human eukaryotic release factors eRF1 mechanism of stop codon recognition and peptidyl-tRNA hydrolysis, Cell 100 (2000) 311-321.

[4] A. Seit-Nebi, L. Frolova, J. Justesen, L. Kisselev, Class-1 translation termination factors: invariant GGQ minidomain is essential for release activity and ribosome binding but not for stop codon recognition, Nucleic Acids Res. 29 (2001) 3982-3987.

[5] L. Chavatte, A. Seit-Nebi, V. Dubovaya, A. Favre, The invariant uridine of stop codons contacts the conserved NIKSR loop of human ERF1 in the ribosome, EMBO J. 21 (2002) 5302-5311.

[6] K.N. Bulygin, Y.S. Khairulina, P.M. Kolosov, A.G. Ven'yaminova, D.M. Graifer, Yu.N. Vorobjev, L.Yu. Frolova, L.L. Kisselev, G.G. Karpova, Three distinct peptides from the $\mathrm{N}$ domain of translation termination factor eRF1 surround stop codon in the ribosome, RNA 16 (2010) 1902-1914.

[7] K.N. Bulygin, Yu.S. Khairulina, P.M. Kolosov, A.G. Ven'yaminova, D.M. Graifer Yu.N. Vorobjev, L.Yu. Frolova, G.G. Karpova, Adenine and guanine recognition of stop codon is mediated by different $\mathrm{N}$ domain conformations of translation termination factoreRF1, Nucleic Acids Res. 39 (2011) 7134-7146.

[8] L.E. Wong, Y. Li, S. Pillay, L. Frolova, K. Pervushin, Selectivity of stop codon recognition in translation termination is modulated by multiple conformations of GTS loop in eRF1, Nucleic Acids Res. 40 (2012) 5751-5765.

[9] D. Taylor, A. Unbehaun, W. Li, S. Das, J. Lei, H.Y. Liao, R.A. Grassucci, T.V. Pestova, J. Frank, Cryo-EM structure of the mammalian eukaryotic release factor eRF1-eRF3associated termination complex, Proc. Natl. Acad. Sci. U. S. A. 109 (2012) 18413-18418.

[10] A. des Georges, Y. Hashem, A. Unbehaun, R.A. Grassucci, D. Taylor, C.U. Hellen, T.V. Pestova, J. Frank, Structure of the mammalian ribosomal pre-termination complex associated with eRF1'eRF3.GDPNP, Nucleic Acids Res. 42 (2014) 3409-3418.

[11] A. Preis, A. Heuer, C. Barrio-Garcia, A. Hauser, D.E. Eyler, O. Berninghausen, R. Green, T. Becker, R. Beckmann, Cryoelectron microscopic structures of eukaryotic translation termination complexes containing eRF1-eRF3 or eRF1-ABCE1, Cell Rep. 8 (2014) 59-65.
[12] A. Brown, S. Shao, J. Murray, R.S. Hegde, V. Ramakrishnan, Structural basis for stop codon recognition in eukaryotes, Nature 524 (2015) 493-496.

[13] M. Muhs, T. Hilal, T. Mielke, M.A. Skabkin, K.Y. Sanbonmatsu, T.V. Pestova, C.M. Spahn, Cryo-EM of ribosomal 80 S complexes with termination factors reveals the translocated cricket paralysis virus IRES, Mol. Cell 57 (2015) 422-432.

[14] S. Matheisl, O. Berninghausen, T. Becker, R. Beckmann, Structure of a human translation termination complex, Nucleic Acids Res. 43 (2015) 8615-8626.

[15] A.V. Pisarev, M.A. Skabkin, V.P. Pisareva, O.V. Skabkina, A.M. Rakotondrafara, M.W. Hentze, C.U. Hellen, T.V. Pestova, The role of ABCE1 in eukaryotic posttermination ribosomal recycling, Mol. Cell 37 (2010) 196-210.

[16] K.N. Bulygin, Y.S. Bartuli, A.A. Malygin, D.M. Graifer, L.Yu. Frolova, G.G. Karpova, Chemical footprinting reveals conformational changes of 18S and 28S rRNAs at different steps of translation termination on the human ribosome, RNA 22 (2016) $278-289$.

[17] L. Chavatte, L.Yu. Frolova, P. Laugaa, L.L. Kisselev, A. Favre, Stop codons and UGG promote efficient binding of the polypeptide release factor eRF1 to the ribosomal A site, J. Mol. Biol. 331 (2003) 745-758.

[18] N.B. Matasova, S.V. Myltseva, M.A. Zenkova, D.M. Graifer, S.N. Vladimirov, G.G. Karpova, Isolation of ribosomal subunits containing intact rRNA from human placenta: estimation of functional activity of 80S ribosomes, Anal. Biochem. 198 (1991) 219-223.

[19] K.N. Bulygin, M.N. Repkova, A.G. Ven'yaminova, D.M. Graifer, G.G. Karpova, L.Yu. Frolova, L.L. Kisselev, Positioning of the mRNA stop signal with respect to polypeptide chain release factors and ribosomal proteins in 80 S ribosomes, FEBS Lett. 514 (2002) 96-101.

[20] C. Hountondji, G. Fayat, S. Blanquet, Complete inactivation and labeling of methionyl-tRNA-synthetase by periodate-treated initiator tRNA in the presence of sodium cyanohydridoborate, Eur. J. Biochem. 102 (1979) 247-250.

[21] L.Yu. Frolova, J.L. Simonsen, T.I. Merkulova, D.Y. Litvinov, P.M. Martensen, V.O. Rechinsky, J.H. Camonis, L.L. Kisselev, J. Justesen, Functional expression of eukaryotic polypeptide chain release factors 1 and 3 by means of baculovirus/insect cells and complex formation between the factors, Eur. J. Biochem. 256 (1998) $36-44$.

[22] L.Yu. Frolova, T.I. Merkulova, L.L. Kisselev, Translation termination in eukaryotes: polypeptide release factor eRF1 is composed of functionally and structurally distinct domains, RNA 6 (2000) 381-390.

[23] L. Frolova, A. Seit-Nebi, L. Kisselev, Highly conserved NIKS tetrapeptide is functionally essential in eukaryotic translation termination factor eRF1, RNA 8 (2002) 129-136.

[24] L. Frolova, X. Le Goff, H.H. Rasmussen, S. Cheperegin, G. Drugeon, M. Kress, I. Arman, A.L. Haenni, J.E. Celis, M. Philippe, J. Justesen, L. Kisselev, A highly conserved eukaryotic protein family possessing properties of polypeptide chain release factor, Nature 372 (1994) 701-703.

[25] L. Frolova, X. Le Goff, G. Zhouravleva, E. Davydova, M. Philippe, L. Kisselev, Eukaryotic polypeptide chain release factor eRF3 is an eRF1- and ribosomedependent guanosine triphosphatase, RNA 2 (1996) 334-341.

[26] C. Hountondji, K. Bulygin, A. Woisard, P. Tuffery, J.B. Crechet, M. Pech, K.H. Nierhaus, G. Karpova, S. Baouz, Lys53 of ribosomal protein L36AL and the CCA end of a tRNA at the P/E hybrid site are in close proximity on the human ribosome, Chembiochem 13 (2012) 1791-1797.

[27] S. Baouz, A. Woisard, S. Sinapah, J.P. Le Caer, M. Argentini, K. Bulygin, G. Aguie, C. Hountondji, The human large subunit ribosomal protein L36A-like contacts the CCA end of P-site bound tRNA, Biochimie 91 (2009) 1420-1425.

[28] J.-J. Madjar, M. Arpin, M. Buisson, J.-P. Reboud, Spot position of rat liver ribosomal proteins by four different two-dimensional electrophoresis in polyacrylamide gel, Mol. Gen. Genet. 171 (1979) 121-134.

[29] M.V. Molotkov, D.M. Graifer, E.A. Popugaeva, K.N. Bulygin, M.I. Meschaninova, A.G. Ven'yaminova, G.G. Karpova, mRNA 3' of the A site bound codon is located close to protein S3 on the human 80S ribosome, RNA Biol. 3 (2006) 122-129.

[30] S.J.S. Hardy, C.G. Kurland, P. Voynow, G. Mora, The ribosomal proteins of Escherichia coli. I. Purification of 30S ribosomal proteins, Biochemistry 8 (1969) 2897-2905.

[31] C. Hountondji, K. Bulygin, J.-B. Créchet, A. Woisard, P. Tuffery, J. Nakayama, L. Frolova, K.H. Nierhaus, G. Karpova, S. Baouz, The CCA-end of P-tRNA contacts both the human RPL36AL and the A-site bound translation termination factor eRF1 at the peptidyl transferase center of the human $80 \mathrm{~S}$ ribosome, Open Biochem. J. 8 (2014) 52-67.

[32] N. Demeshkina, E. Laletina, M. Meschaninova, A. Ven'yaminova, D. Graifer, G. Karpova, Positioning of mRNA codons with respect to 18S rRNA at the P and E sites of human ribosome, Biochim. Biophys. Acta 1627 (2003) 39-46.

[33] D.E. Sharifulin, A.S. Grosheva, Y.S. Bartuli, A.A. Malygin, M.I. Meschaninova, A.G. Ven'yaminova, J. Stahl, D.M. Graifer, G.G. Karpova, Molecular contacts of ribose-phosphate backbone of mRNA with human ribosome, Biochim. Biophys. Acta 1849 (2015) 930-939.

[34] K.N. Bulygin, D.M. Graifer, M.N. Repkova, I.A. Smolenskaya, A.G. Veniyaminova, G.G. Karpova, Nucleotide G-1207 of 18S rRNA is an essential component of the human 80S ribosomal decoding center, RNA 3 (1997) 1480-1485.

[35] N. Demeshkina, M. Repkova, A. Ven'yaminova, D. Graifer, G. Karpova, Nucleotides of $18 \mathrm{~S}$ rRNA surrounding mRNA codons at the human ribosomal A, P and E sites, respectively: a cross-linking study with mRNA analogues carrying aryl azide group at either the uracil or the guanine residue, RNA 6 (2000) 1727-1736.

[36] D. Graifer, M. Molotkov, V. Styazhkina, N. Demeshkina, K. Bulygin, A. Eremina, A. Ivanov, E. Laletina, A. Ven'yaminova, G. Karpova, Variable and conserved elements of human ribosomes surrounding the mRNA at the decoding and upstream sites, Nucleic Acids Res. 32 (2004) 3282-3293.

[37] A.V. Pisarev, V.G. Kolupaeva, M.M. Yusupov, C.U. Hellen, T.V. Pestova, Ribosomal 
position and contacts of mRNA in eukaryotic translation initiation complexes, EMBO J. 27 (2008) 1609-1621.

[38] J. Khairulina, D. Graifer, K. Bulygin, A. Ven'yaminova, L. Frolova, G. Karpova, Eukaryote-specific motif of ribosomal protein S15 neighbors A site codon during elongation and termination of translation, Biochimie 92 (2010) 820-825.

[39] T.V. Budkevich, J. Giesebrecht, E. Behrmann, J. Loerke, D.J. Ramrath, T. Mielke, J. Ismer, P.W. Hildebrand, C.S. Tung, K.H. Nierhaus, K.Y. Sanbonmatsu, C.M. Spahn, Regulation of the mammalian elongation cycle by subunit rolling: a eukaryotic-specific ribosome rearrangement, Cell 158 (2014) 121-131.

[40] J. Rabl, M. Leibundgut, S.F. Ataide, A. Haag, N. Ban, Crystal structure of the eukaryotic 40S ribosomal subunit in complex with initiation factor 1, Science 331 (2011) 730-736.

[41] A. Ben-Shem, N. Garreau de Loubresse, S. Melnikov, L. Jenner, G. Yusupova, M. Yusupov, The structure of the eukaryotic ribosome at 3.0 A resolution, Science (New York, N.Y.) 334 (2011) 1524-1529.

[42] A.M. Anger, J.P. Armache, O. Berninghausen, M. Habeck, M. Subklewe, D.N. Wilson, R. Beckmann, Structures of the human and Drosophila 80S ribosome, Nature 497 (2013) 80-85.
[43] H. Khatter, A.G. Myasnikov, S.K. Natchiar, B.P. Klaholz, Structure of the human 80 S ribosome, Nature 520 (2015) 640-645.

[44] D. Graifer, G. Karpova, A strategy for determination of protein sites involved in interactions with RNA ligands in the human translational machinery, Protein Purification and Analysis I. Methods and Applications, iConcept Press Ltd., Hong Kong, 2013, pp. 57-76 (ISBN 978-1-922227-19-5).

[45] T. Becker, S. Franckenberg, S. Wickles, C.J. Shoemaker, A.M. Anger, J.P. Armache, H. Sieber, C. Ungewickell, O. Berninghausen, I. Daberkow, A. Karcher, M. Thomm, K.P. Hopfner, R. Green, R. Beckmann, Structural basis of highly conserved ribosome recycling in eukaryotes and archaea, Nature 482 (2012) 501-506.

[46] E.Z. Alkalaeva, A.V. Pisarev, L.Y. Frolova, L.L. Kisselev, T.V. Pestova, In vitro reconstitution of eukaryotic translation reveals cooperativity between release factors eRF1 and eRF3, Cell 125 (2006) 1125-1136.

[47] D. Graifer, G. Karpova, Roles of ribosomal proteins in the functioning of translational machinery of eukaryotes, Biochimie 109 (2015) 1-17.

[48] S. Shao, J. Murray, A. Brown, J. Taunton, V. Ramakrishnan, R.S. Hegde, Decoding mammalian ribosome-mRNA states by translational GTPase complexes, Cell 167 (2016) (1229-1240.e15). 